\title{
Efficacy and safety of once-daily glycopyrronium in predominantly Chinese patients with moderate-to-severe chronic obstructive pulmonary disease: the GLOW7 study
}

\author{
This article was published in the following Dove Press journal: \\ International Journal of COPD \\ 5 January 2015 \\ Number of times this article has been viewed
}

\author{
Chen Wang' \\ Tieying Sun' \\ Yijiang Huang ${ }^{2}$ \\ Michael Humphries ${ }^{3}$ \\ Lingyan $\mathrm{Bai}^{3}$ \\ Lilly $\mathrm{Li}^{3}$ \\ Qian Wang ${ }^{3}$ \\ Pearl Kho ${ }^{4}$ \\ Roz Firth ${ }^{4}$ \\ Peter D'Andrea ${ }^{5}$ \\ 'Beijing Hospital, Dongcheng District, \\ Beijing, People's Republic of China; \\ ${ }^{2}$ Hainan Provincial People's Hospital, \\ Xiuying District, Haikou, People's \\ Republic of China; ${ }^{3}$ Beijing Novartis \\ Pharma Co Ltd, Zhangjiang Hi-Tech \\ Park, Shanghai, People's Republic of \\ China; ${ }^{4}$ Novartis Horsham Research \\ Centre, Horsham, West Sussex, \\ UK; ${ }^{5}$ Novartis Pharmaceuticals \\ Corporation, East Hanover, NJ, USA
}

Correspondence: Chen Wang China-Japan Friendship Hospital, 2 Yinghua Dongjie, Chaoyang District, Beijing, 100029, People's Republic of China Tel +86 I39 0 I I 2992 Email cyh-birm@263.net
Background: Glycopyrronium is a once-daily (od) long-acting muscarinic antagonist for the maintenance treatment of chronic obstructive pulmonary disease (COPD). The GLOW7 study evaluated the efficacy and safety of od glycopyrronium $50 \mu \mathrm{g}$ in predominantly Chinese patients with moderate-to-severe COPD.

Methods: In this 26-week, multi-center, double-blind, placebo-controlled, parallel-group study, men and women $\geq 40$ years with moderate-to-severe COPD were randomized to glycopyrronium $50 \mu \mathrm{g}$ od or placebo $(2: 1)$. The primary objective was to confirm the significant improvement of trough forced expiratory volume in 1 second $\left(\mathrm{FEV}_{1}\right)$ following 12 weeks of treatment with glycopyrronium compared with placebo. Secondary objectives included the effect of glycopyrronium on health status (St George's Respiratory Questionnaire), breathlessness (Transition Dyspnea Index), other lung function parameters, rescue medication use, and COPD exacerbations. Safety and tolerability were also evaluated.

Results: Of the 460 patients randomized, 459 were included in the full analysis set (glycopyrronium, $n=306$; placebo, $n=154$; mean age 64.7 years; mean post-bronchodilator $\mathrm{FEV}_{1}: 50.8 \%$ predicted); 425 (92.4\%) completed the study. At Week 12, glycopyrronium significantly improved trough $\mathrm{FEV}_{1}$ with a least square means treatment difference of $141 \mathrm{~mL}(95 \%$ confidence interval $111 \mathrm{~mL}, 171 \mathrm{~mL} ; P<0.001)$ compared with placebo. The mean treatment effect of glycopyrronium was greater than the minimum clinically important difference versus placebo in both St George's Respiratory Questionnaire total score $(-4.92 ; P<0.001)$ and Transition Dyspnea Index focal score $(1.0 ; P<0.001)$ at week 26 . Glycopyrronium reduced the risk of exacerbations in terms of time to first moderate or severe exacerbation by $28 \%(P=0.153)$ and rate of moderate or severe COPD exacerbation by $29 \%(P=0.119)$ compared with placebo. Incidence of death was $1.3 \%$ with glycopyrronium and $0 \%$ in placebo during the treatment period. Overall incidence of adverse events (glycopyrronium 43.6\%; placebo 47.4\%) and serious adverse events (glycopyrronium 5.6\%; placebo 9.1\%) were similar.

Conclusion: In predominantly Chinese patients with moderate-to-severe COPD, od glycopyrronium $50 \mu \mathrm{g}$ significantly improved lung function, dyspnea, and health status compared with placebo. The safety and tolerability profile of glycopyrronium was comparable to placebo.

Keywords: bronchodilation, COPD, dyspnea, exacerbations, glycopyrronium, health status

\section{Introduction}

Chronic obstructive pulmonary disease (COPD) is a progressive disease characterized by persistent airflow limitation, associated with an enhanced inflammatory response. The global economic and social burden of COPD is increasing substantially and is projected 
to be the third leading cause of death by $2020 .{ }^{1}$ In the People's Republic of China, the overall prevalence of COPD in people aged $>40$ years was $8.2 \%$, which varied widely among locations across the country, from $5 \%$ to $13 \% .^{2}$

Inhaled long-acting bronchodilators including long-acting $\beta_{2}$-agonists and long-acting muscarinic antagonists (LAMAs) are the mainstay for the maintenance treatment of COPD. ${ }^{3}$ Inhaled glycopyrronium (Seebri ${ }^{\circledR}$ Breezhaler ${ }^{\circledR}$ capsules; NVA237; Novartis Pharma AG, Basel, Switzerland) is a oncedaily (od) LAMA approved in various countries as maintenance bronchodilator for symptomatic treatment of adult patients with COPD. ${ }^{3}$ In earlier Phase III GLycopyrronium bromide in COPD airWays (GLOW) clinical studies, predominantly in Caucasian populations, glycopyrronium monotherapy at a dose of $50 \mu \mathrm{g}$ od via the Breezhaler ${ }^{\circledR}$ device exhibited a rapid onset of action with a superior 24 hour sustained bronchodilation with a comparable safety profile to placebo. ${ }^{4,5}$ Improvements in dyspnea, health status, risk of moderate or severe COPD exacerbations, and rescue medication use with glycopyrronium were significant versus placebo and comparable to open-label tiotropium $18 \mu \mathrm{g}$ od. ${ }^{5}$ A significant improvement in trough forced expiratory volume in 1 second $\left(\mathrm{FEV}_{1}\right)$ was observed with glycopyrronium after the first dose on Day 1 both versus placebo and tiotropium. ${ }^{6}$ Glycopyrronium showed similar efficacy and safety compared with tiotropium in both open-label $^{5}$ and double-blind ${ }^{7}$ randomized clinical studies. Exercise tolerance was improved significantly with glycopyrronium compared with placebo from Day 1, accompanied by sustained reductions in lung hyperinflation. ${ }^{8}$

Ethnic differences among patient populations may affect the treatment outcomes because of potential differences in pharmacologic factors including pharmacokinetics and pharmacodynamics. ${ }^{9}$ A clear difference in COPD prevalence, smoking status, disease severity, management, and hospital admissions was found by ethnicity among COPD population. ${ }^{10}$ Previous studies of glycopyrronium have predominantly involved Caucasian populations, with little information regarding Asians. The role of ethnicity in response variability to a pharmacologic intervention has been highlighted previously. ${ }^{11}$

This GLOW7 study evaluated the efficacy and safety of od glycopyrronium $50 \mu \mathrm{g}$ via the Breezhaler ${ }^{\circledR}$ device versus placebo in predominantly Chinese patients with moderateto-severe COPD.

\section{Methods}

\section{Patients}

Men and women $\geq 40$ years of age, current or ex-smokers with a smoking history of at least 10 pack-years, postbronchodilator $\mathrm{FEV}_{1} \geq 30 \%$ and $<80 \%$ of predicted normal, and post-bronchodilator $\mathrm{FEV}_{1}$ to forced vital capacity (FVC) ratio $<0.70$ were enrolled in the GLOW7 study. Patients with a history of COPD exacerbations, requiring treatment with antibiotics, systemic steroids (oral or intravenous), or hospitalization in the 6 weeks prior to screening or any time prior to randomization were excluded from the study. More details about inclusion and exclusion criteria are given in the Supplementary material.

\section{Study design}

This was a multicenter, double-blind, placebo-controlled, parallel-group study (Figure 1). The study was conducted in 37 centers in four countries (People's Republic of China, Korea, India, and the Philippines). The majority of centers were in the People's Republic of China (25 centers). All patients provided written informed consent before participating in the study. In the 7-day pre-screening washout period, patients discontinued using long-acting $\beta_{2}$-agonist

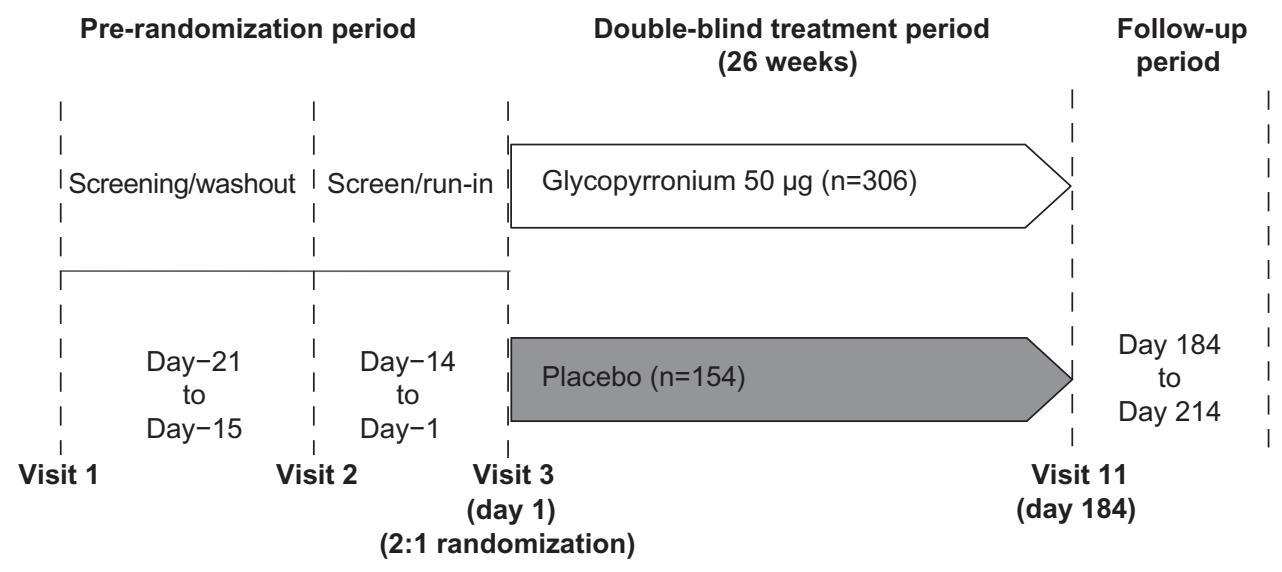

Figure I Study design. 
and inhaled corticosteroids (ICS) combination therapy and were switched to equivalent ICS monotherapy. Patients' eligibility based on symptom control via daily electronic diary was assessed during the 14 day run-in period. Eligible patients were randomized (2:1) to od glycopyrronium $50 \mu \mathrm{g}$ or placebo (both via the Breezhaler ${ }^{\circledR}$ device) to be taken in the morning between 8 am and 11 am, for a period of 26 weeks. Randomization was stratified according to baseline smoking status. Salbutamol/albuterol was permitted as rescue medication throughout the study. The study was approved by institutional review boards and ethics committees at participating centers, and was conducted in accordance with the Declaration of Helsinki and the International Conference on Harmonization Good Clinical Practice guidelines.

\section{Assessments}

\section{Efficacy}

Spirometry measurements $\left(\mathrm{FEV}_{1}\right.$ and $\left.\mathrm{FVC}\right)$ were taken to assess patients' eligibility before the run-in period and to measure the post-bronchodilator $\mathrm{FEV}_{1} 45$ minutes after inhalation of $4 \times 20 \mu \mathrm{g}$ of ipratropium bromide (or equivalent dose). Thereafter, spirometry measurements were taken at randomization, Days 1, 2, 29, 85, 86 and 183 and 184 and at the time of discontinuation for patients who discontinued prematurely.

The primary objective of the study was to confirm the significant improvement with glycopyrronium delivered via the Breezhaler ${ }^{\circledR}$ device versus placebo on trough $\mathrm{FEV}_{1}$ (mean of $\mathrm{FEV}_{1}$ at $11.15 \mathrm{pm}$ and $11.45 \mathrm{pm}$ post dose) after 12 weeks of treatment in patients with COPD.

Secondary objectives were to evaluate the improvements in health status according to St George's Respiratory Questionnaire (SGRQ) total score and dyspnea measured using the Transition Dyspnea Index (TDI) at Weeks 12 and 26. Improvements in other lung function parameters such as peak $\mathrm{FEV}_{1}$ (defined as the maximum $\mathrm{FEV}_{1} 5$ minutes to 4 hours post-dose), standardized area under the curve (AUC) from 5 minutes to 4 hours for $\mathrm{FEV}_{1}\left(\mathrm{FEV}_{1} \mathrm{AUC}_{5 \min -4 \mathrm{~h}}\right)$ and trough FVC were evaluated throughout the study (Day 1, Weeks 12 and 26).

Other secondary objectives including effect of glycopyrronium on COPD exacerbations in terms of time to first exacerbations and rate of exacerbations and reduction in daily rescue medication use compared with placebo during the 26 weeks of treatment were also evaluated. An exploratory objective of the study was impact of glycopyrronium compared with placebo on medical resource utilization during the 26 weeks of treatment.

\section{Safety}

Safety assessments consisted of monitoring adverse events (AEs) and serious adverse events (SAEs) and monitoring vital signs (pulse rate and systolic and diastolic blood pressure), and laboratory analyses (hematology, clinical chemistry, and urinalysis) during the 26 week treatment and 30 days follow-up period. Cause of death, non-fatal serious cardio- and cerebrovascular (CCV) events, as well as all atrial fibrillation and atrial flutter events occurring during the study and follow-up period were evaluated by an independent adjudication committee.

\section{Statistical analysis}

Summary statistics were used to describe demographics and baseline patient characteristics based on safety set, which included all patients who received at least one dose of study drug whether or not being randomized. Efficacy analysis was performed in the full analysis set, defined as all randomized patients who received at least one dose of the study drug. Primary efficacy variable, trough $\mathrm{FEV}_{1}$ at Week 12 was analyzed using a mixed model with last observation carried forward, including treatment as a fixed effect, baseline $\mathrm{FEV}_{1}$ measurement, $\mathrm{FEV}_{1}$ prior to inhalation of short acting bronchodilator, $\mathrm{FEV}_{1} 45$ minutes post inhalation of short acting bronchodilator as covariates. The model also included baseline ICS use (yes/no), smoking status (current/ex-smoker) and region (People's Republic of China/other) as fixed effects with center nested within region as a random effect. Other efficacy variables were analyzed using the similar mixed model using corresponding baseline measurement replacing baseline $\mathrm{FEV}_{1}$. The percentage of patients with clinically important improvement of SGRQ total score and TDI focal score was analyzed using logistic regression. The model included the same terms as described above. Time to first moderate or severe COPD exacerbation was analyzed using a Cox regression model and displayed by Kaplan-Meier curves. The Cox regression model included terms for treatment, baseline ICS use (yes/no), baseline total symptom score, baseline COPD exacerbation history, $\mathrm{FEV}_{1}$ prior to inhalation of short acting bronchodilator, FEV 45 minutes post inhalation of short acting bronchodilator, smoking status, and region. The rate of moderate or severe COPD exacerbations during the 26 weeks of treatment was analyzed using a generalized linear model assuming a negative binomial distribution. The log (time on treatment) was used as the offset variable in the model. The model included the same terms as used for the analysis of time to first moderate or severe COPD exacerbation. Safety assessment was conducted using summary statistics 


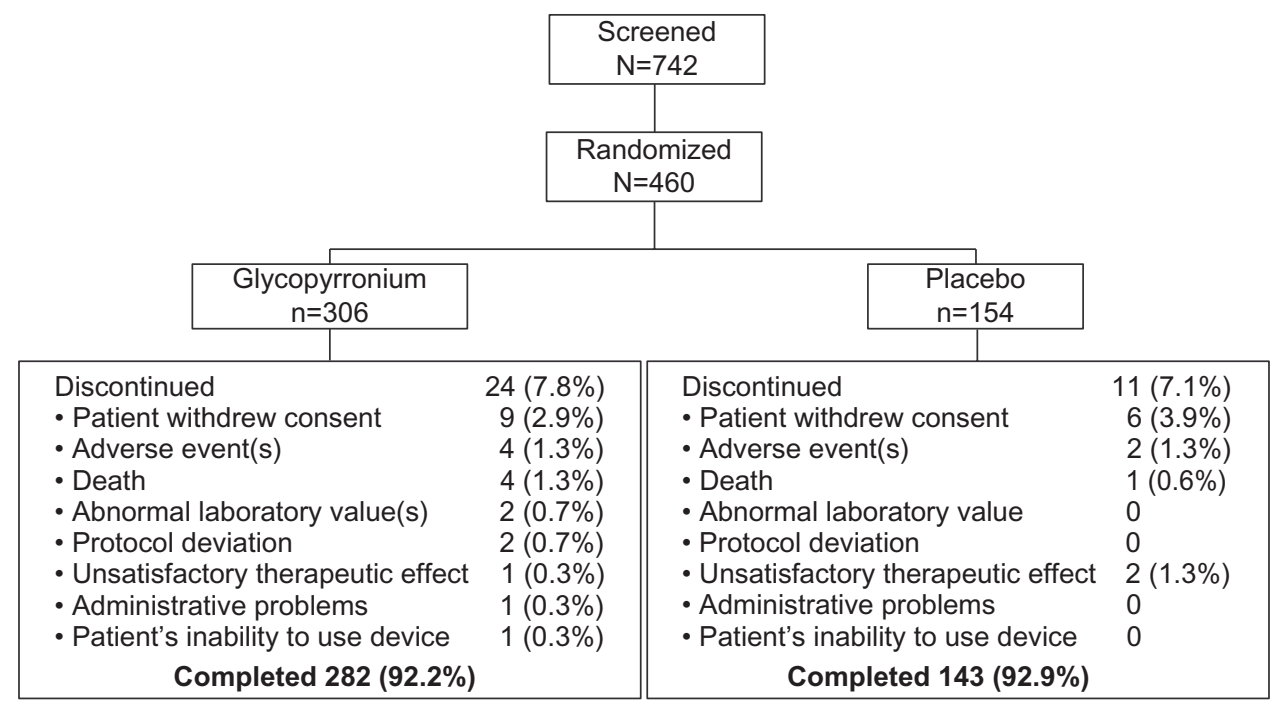

Figure 2 Patients' dispositions.

based on safety set. Sample size calculation is given in the Supplementary material.

\section{Results}

\section{Patient disposition and baseline characteristics}

A total of 742 patients were screened; 460 patients were randomized in a 2:1 ratio to glycopyrronium $(\mathrm{n}=306)$ or placebo ( $\mathrm{n}=154) ; 425$ (92.4\%) completed the study (Figure 2). Patients' discontinuation due to AEs was similar between the treatment groups (both 1.3\%). Patient demographics and baseline clinical characteristics were broadly similar between glycopyrronium and placebo as shown in Table 1. Most of the patients were Chinese (79.5\%). Overall, the majority of patients $(76.3 \%)$ were without moderate-tosevere COPD exacerbations over the previous 12 months prior to screening.

\section{Efficacy}

\section{Spirometry}

This study confirmed the statistical superiority of od glycopyrronium in improving trough $\mathrm{FEV}_{1}$ at Week 12 (primary objective) compared with placebo (Figure 3). Glycopyrronium showed a least square means (LSM) treatment difference of $141 \mathrm{~mL}(95 \%$ confidence interval [CI] $111 \mathrm{~mL}, 171 \mathrm{~mL} ; P<0.001)$ in trough $\mathrm{FEV}_{1}$ compared with placebo at Week 12. In the subgroup of Chinese patients with $\mathrm{COPD}$, trough $\mathrm{FEV}_{1}$ was significantly $(P<0.001)$ improved with glycopyrronium versus placebo at Week 12 with an LSM treatment difference of $137 \mathrm{~mL}$ (95\% CI: $103 \mathrm{~mL}, 171 \mathrm{~mL}$ ). Significant improvement in trough $\mathrm{FEV}_{1}$ as early as Day 1 (LSM treatment difference $121 \mathrm{~mL}$; 95\% CI: $99 \mathrm{~mL}, 142 \mathrm{~mL}$;
$P<0.001$ ) and at Week 26 (LSM treatment difference $137 \mathrm{~mL}$; 95\% CI, $102 \mathrm{~mL}, 171 \mathrm{~mL} ; P<0.001$ ) was observed with glycopyrronium compared with placebo. A significant $(P<0.001)$ improvement in $\mathrm{FEV}_{1}$ (LSM treatment difference $87 \mathrm{~mL}$ ) versus placebo was observed at 5 minutes post-dose on Day 1 of glycopyrronium treatment. Improvement in trough $\mathrm{FEV}_{1}$ at Week 12 with glycopyrronium compared with placebo was statistically and clinically significant regardless of age, sex, smoking history, COPD severity, baseline ICS use, and ethnicity (Figure 4).

Glycopyrronium was superior to placebo in terms of improvement in other lung function parameters such as peak $\mathrm{FEV}_{1}$ during 5 minutes to 4 hours post-dose, $\mathrm{FEV}_{1}$ $\mathrm{AUC}_{5 \text { min-4h }}$ and trough FVC on Day 1, Week 12, and Week 26 (Table 2).

\section{SGRQ total score and TDI focal score}

Improvement in SGRQ total score and TDI focal score with glycopyrronium compared with placebo at Weeks 12 and

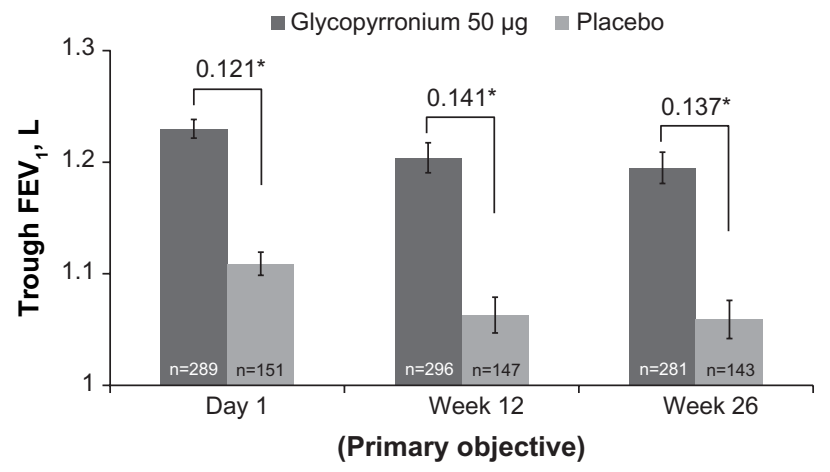

Figure 3 Improvement in trough forced expiratory volume in I second $\left(\mathrm{FEV}_{1}\right)$ on Day I, Week 12 and Week 26.

Notes: Data are least square means (standard error); $* p<0.001$. 
Table I Demographics and baseline clinical characteristics (safety set)

\begin{tabular}{|c|c|c|}
\hline & $\begin{array}{l}\text { Glycopyrronium } \\
(n=305)\end{array}$ & $\begin{array}{l}\text { Placebo } \\
(n=154)\end{array}$ \\
\hline Age, years & $64.6(7.84)$ & $65.0(8.29)$ \\
\hline \multicolumn{3}{|l|}{ Sex, n (\%) } \\
\hline Male & $294(96.4)$ & $145(94.2)$ \\
\hline \multicolumn{3}{|l|}{ Ethnicity, n (\%) } \\
\hline Chinese & $246(80.7)$ & $119(77.3)$ \\
\hline Indian & $5(1.6)$ & $5(3.2)$ \\
\hline Filipino & $27(8.9)$ & $13(8.4)$ \\
\hline Korean & $27(8.9)$ & $17(I 1.0)$ \\
\hline \multicolumn{3}{|l|}{ Severity of COPD, n (\%) } \\
\hline Moderate & $150(49.2)$ & $82(53.2)$ \\
\hline Severe & $155(50.8)$ & $72(46.8)$ \\
\hline COPD duration, years & $4.5(5.3 \mathrm{I})$ & $4.3(5.00)$ \\
\hline \multicolumn{3}{|c|}{ COPD exacerbation history, n (\%) } \\
\hline 0 exacerbation & $24 \mid(79.0)$ & $109(70.8)$ \\
\hline I exacerbation & $47(I 5.4)$ & $3 I(20.1)$ \\
\hline$>2$ exacerbations & $17(5.6)$ & $14(9.1)$ \\
\hline ICS use, n (\%) & $198(64.9)$ & $86(55.8)$ \\
\hline \multicolumn{3}{|l|}{ Smoking history, n (\%) } \\
\hline Ex-smoker & $237(77.7)$ & $120(77.9)$ \\
\hline Current smoker & $68(22.3)$ & $34(22.1)$ \\
\hline Duration of smoking, pack-years & $38.3(20.78)$ & $38.3(21.13)$ \\
\hline Pre-bronchodilator $\mathrm{FEV}_{1}, \mathrm{~L}$ & $1.13(0.379)$ & $1.13(0.383)$ \\
\hline $\begin{array}{l}\text { Pre-bronchodilator } \mathrm{FEV}_{1}, \% \\
\text { predicted }\end{array}$ & $42.83(12.055)$ & $44.49(12.848)$ \\
\hline Post-bronchodilator $\mathrm{FEV}_{1}$, L & $\mathrm{I} .33(0.400)$ & $\mathrm{I} .33(0.394)$ \\
\hline $\begin{array}{l}\text { Post-bronchodilator } \mathrm{FEV}_{1}, \% \\
\text { predicted }\end{array}$ & $50.20(|2.42|)$ & $51.88(12.449)$ \\
\hline FEV , reversibility, \% increase & $18.89(12.761)$ & $18.82(11.835)$ \\
\hline Post-bronchodilator FEV/FVC, \% & $42.72(9.894)$ & $44.03(10.994)$ \\
\hline
\end{tabular}

Note: Data are mean (SD) unless otherwise stated.

Abbreviations: COPD, chronic obstructive pulmonary disease; $\mathrm{FEV}_{1}$, forced expiratory volume in I second; FVC, forced vital capacity; ICS, inhaled corticosteroid; $\mathrm{SD}$, standard deviation.
26 is shown in Figures 5 and 6, respectively. Glycopyrronium showed statistically significant improvement over placebo and exceeded minimum clinically important difference (MCID) in SGRQ total score with an LSM treatment difference of $-5.04(P<0.001)$ and $-4.92(P<0.001)$ at Weeks 12 and 26 , respectively. Pre-defined MCID in TDI focal score was also achieved with glycopyrronium versus placebo at both Weeks 12 and 26 (LSM treatment difference 1.2 and 1.0, respectively; both $P<0.001)$. The percentage of patients with clinical meaningful improvement in SGRQ total score $(\geq 4$ point reduction; Figure 5) and TDI focal score ( $\geq 1$ point improvement; Figure 6) was higher with glycopyrronium compared with placebo at Weeks 12 and 26.

\section{COPD exacerbation and rescue medication}

A trend towards delay in time to first moderate or severe COPD exacerbation (hazard ratio $0.72 ; P=0.153$ ) was observed in the glycopyrronium group compared with placebo, with higher percentage of event-free rates (glycopyrronium $83.2 \%$ : placebo $77.2 \%$ ) during the 26 weeks treatment period (Figure 7). Glycopyrronium reduced the rate of moderate or severe exacerbations versus placebo by $29 \%$ (annualized rate of exacerbation 0.42 versus 0.59 ; rate ratio $0.71: P=0.119$ ).

Use of daily rescue medication over the 26 weeks of treatment was numerically lower with glycopyrronium than placebo (Table 2).

\section{Exploratory objective}

A summary of resource utilization over the 26 weeks of treatment is shown in Table 3. The majority of patients $(95.9 \%$

Table 2 Improvement in lung function and reduction in rescue medication use and symptom score during the GLOW7 study

\begin{tabular}{|c|c|c|c|}
\hline & Glycopyrronium & Placebo & $\begin{array}{l}\text { Treatment difference } \\
\text { (glycopyrronium versus placebo) }\end{array}$ \\
\hline \multicolumn{4}{|l|}{ Peak FEV ${ }_{1}$, L } \\
\hline Day I & $1.38(0.012)$ & $1.18(0.015)$ & $0.193(0.015)^{* *}$ \\
\hline Week 12 & $\mathrm{I} .35(0.02 \mathrm{I})$ & $1.14(0.025)$ & $0.207(0.024)^{* *}$ \\
\hline Week 26 & I.3I (0.025) & I.II (0.030) & $0.196(0.030)^{* *}$ \\
\hline \multicolumn{4}{|l|}{$\mathrm{FEV}_{1} \mathrm{AUC}_{5 \min -4 \mathrm{~h}}, \mathrm{~L}$} \\
\hline Day I & $1.31(0.012)$ & $1.12(0.014)$ & $0.194(0.013)^{* *}$ \\
\hline Week 12 & $1.29(0.020)$ & $1.08(0.024)$ & $0.206(0.023)^{* *}$ \\
\hline Week 26 & $1.24(0.023)$ & $1.05(0.028)$ & $0.197(0.029)^{* *}$ \\
\hline \multicolumn{4}{|l|}{ Trough FVC, L } \\
\hline Day I & $2.97(0.026)$ & $2.74(0.030)$ & $0.230(0.029)^{* *}$ \\
\hline Week 12 & $2.89(0.035)$ & $2.65(0.04 I)$ & $0.245(0.036)^{* *}$ \\
\hline Week 26 & $2.90(0.038)$ & $2.68(0.044)$ & $0.223(0.039)^{* *}$ \\
\hline Change from baseline in mean daily number of puffs & $-0.77(0.157)$ & $-0.55(0.186)$ & $-0.23(0.18 \mathrm{I})^{\mathrm{ns}}$ \\
\hline Percentage of days with no rescue medication use & $41.81(2.785)$ & $37.80(3.206)$ & $4.01(2.835)^{\mathrm{ns}}$ \\
\hline Change from baseline in mean daily total symptom score & $-1.16(0.143)$ & $-0.85(0.164)$ & $-0.31(0.146)^{*}$ \\
\hline
\end{tabular}

Notes: Data are least square means (standard error); ${ }^{*} P<<0.001 ; * P<0.05$; ns not significant.

Abbreviations: AUC, area under the curve; FEV ${ }_{1}$, forced expiratory volume in I second; FVC, forced vital capacity; SE, standard error. 


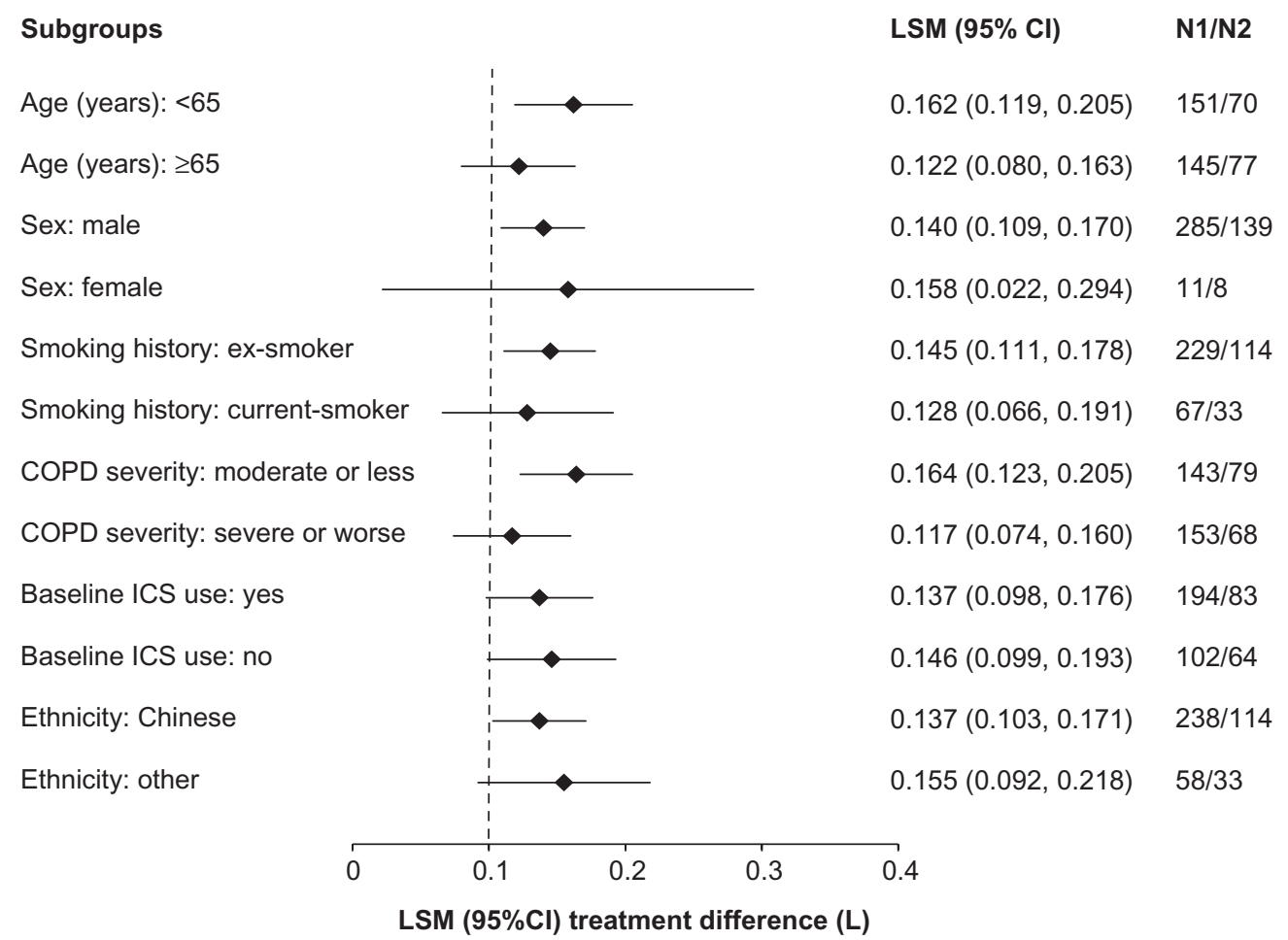

Figure 4 Forest plot of the treatment differences between glycopyrronium and placebo in trough forced expiratory volume in I second (FEV) by subgroups at Week 12. Notes: All $P$-values are $P<0.001$ except female subgroup $(P=0.023)$; NI, number of patients analyzed in the glycopyrronium group; N2, number of patients analyzed in the placebo group. Dotted line represents minimum clinically important difference in trough $\mathrm{FEV}(\mathrm{I} 00 \mathrm{~mL})$.

Abbreviations: $\mathrm{Cl}$, confidence interval; COPD, chronic obstructive pulmonary disease; LSM, least square mean; ICS, inhaled corticosteroids.

overall) had no hospital admission, and the percentage of patients with at least one hospital admission was slightly lower in the glycopyrronium group $(3.3 \%)$ than the placebo group (5.8\%).

\section{Safety}

The percentage of patients experiencing at least one AE during the treatment period was similar between glycopyrronium
(43.6\%) and placebo (47.4\%; Table 4). The proportion of patients with SAEs was $5.6 \%$ (17 patients) in the glycopyrronium group and $9.1 \%$ (14 patients) in the placebo group. Comparable incidence of CCV events was observed between glycopyrronium (2.0\%) and placebo (1.9\%). Adjudicated CCV SAEs were reported in five patients (1.6\%) in the glycopyrronium group with serious $\mathrm{CCV}$ event; two of these patients had major adverse cardiovascular events compared with no patients

Glycopyrronium $50 \mu \mathrm{gg} \square$ Placebo
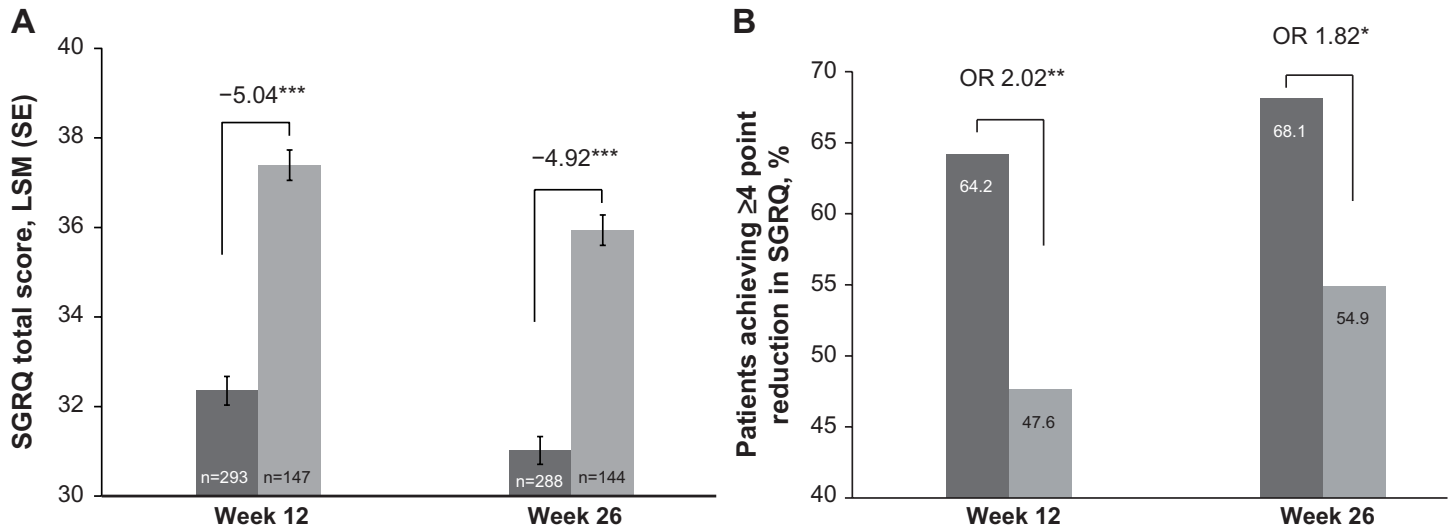

Figure 5 Improvement (A) and percentage of patients with MCID (B) in SGRQ total score at Week I2 and Week 26. Notes: $* * * P<0.001$; $* * P<0.01 ; * P<0.05$

Abbreviations: LSM, least square mean; MCID, minimum clinically important difference; OR, odds ratio; SE, standard error; SGRQ, St George's Respiratory Questionnaire. 

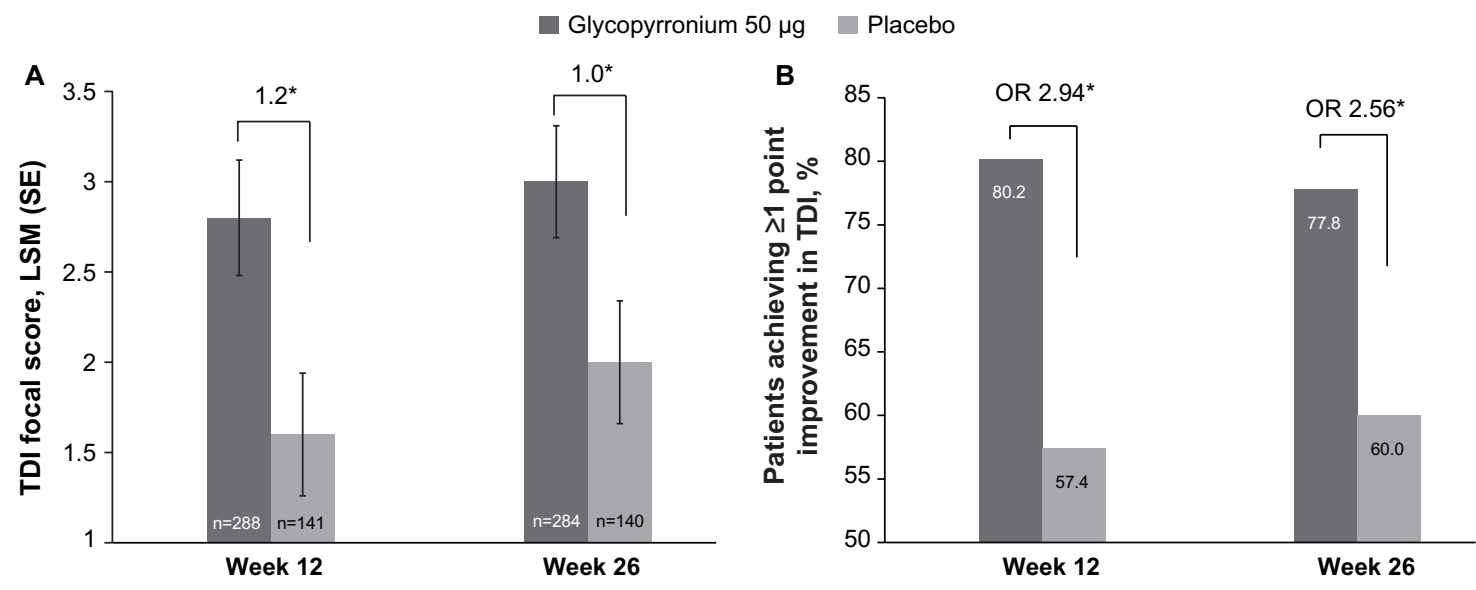

Figure 6 Improvement (A) and percentage of patients with MCID (B) in TDI focal score at Week I2 and Week 26.

Note: $* P<0.001$.

Abbreviations: LSM, least square mean; MCID, minimum clinically important difference; OR, odds ratio; SE, standard error; TDI, Transition Dyspnea Index.

in the placebo group. Four patients died in the glycopyrronium group $(1.3 \%)$ during the treatment period, whereas no patient died in the placebo group. However, one placebo treated patient $(0.6 \%)$ died in the 30 days follow-up period. Of those in the glycopyrronium group, two were due to cardiovascular causes (sudden death and hemorrhagic stroke) and two were due to respiratory causes (COPD exacerbation with and without pneumonia). Two patients who died because of cardiovascular causes had cardiovascular risk factors at baseline. The respiratory death cases were considered related to the underlying disease COPD and not related to study medication.

There were no new occurrences of atrial fibrillation or atrial flutter, and the incidence of recurrent/persistent atrial fibrillation/flutter was similar between the glycopyrronium (two patients, $0.7 \%$ ) and placebo (one patient, $0.6 \%$ ). There were no corrected QT interval (QTc) values of $>500 \mathrm{msec}$ or increases from baseline of $>60 \mathrm{msec}$ reported during this study. QTc values of $>450 \mathrm{msec}$ were reported for a higher proportion of patients in the glycopyrronium group

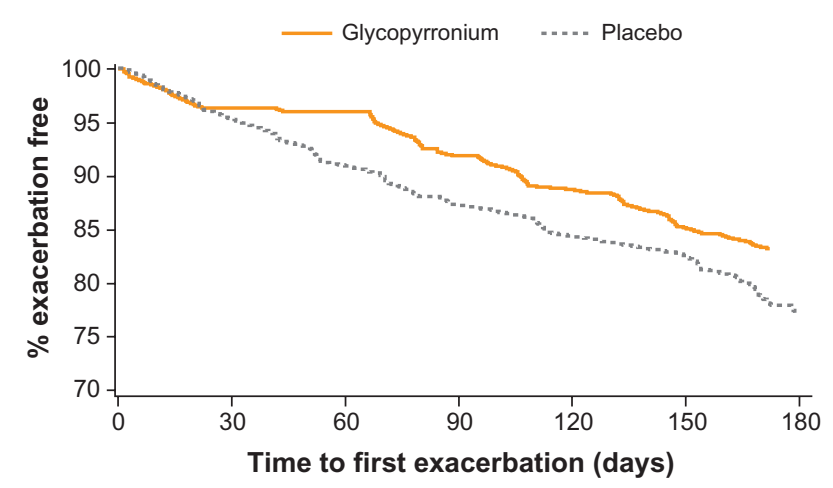

Figure 7 Kaplan-Meier plot of the time to first moderate or severe chronic obstructive pulmonary disease exacerbation.
(17 patients; $5.6 \%$ ) than in the placebo group (three patients; $1.9 \%$ ), whereas the increase from baseline in QTc values was 30-60 msec for a comparable proportion of patients in both treatment groups (glycopyrronium 5.9\% versus placebo $5.2 \%)$.

There were no clinically meaningful differences in routine hematology, clinical chemistry, and urinalysis as well as vital signs and electrocardiogram (ECG) between the treatment groups.

\section{Discussion}

Besides improvement in lung function, the overview of management of stable COPD as per the current Global Initiative for Chronic Obstructive Lung Disease (GOLD) strategy primarily focuses on reduction in symptoms, improvement in health status, exercise tolerance, and reduction in the frequency and severity of exacerbations. This was the first study

Table 3 Summary of resource utilization over the 26 week treatment period

\begin{tabular}{|c|c|c|}
\hline & $\begin{array}{l}\text { Glycopyrronium } \\
(n=305)\end{array}$ & $\begin{array}{l}\text { Placebo } \\
(n=154)\end{array}$ \\
\hline \multicolumn{3}{|l|}{ Hospital admissions, n (\%) } \\
\hline 0 & $295(96.7)$ & 145 (94.2) \\
\hline$\geq 1$ & $10(3.3)$ & $9(5.8)$ \\
\hline $\begin{array}{l}\text { Mean }(S D) \text { total length of } \\
\text { hospitalization, nights }\end{array}$ & I4.I (8.57) & I 3.9 (8.72) \\
\hline \multicolumn{3}{|l|}{ ER visits, $\mathrm{n}(\%)$} \\
\hline 0 & $302(99.0)$ & I 52 (98.7) \\
\hline$\geq 1$ & $3(1.0)$ & $2(1.3)$ \\
\hline \multicolumn{3}{|c|}{ Unscheduled doctor visit, n (\%) } \\
\hline 0 & $293(96.1)$ & $139(90.3)$ \\
\hline$\geq 1$ & $12(3.9)$ & $15(9.7)$ \\
\hline
\end{tabular}

Abbreviations: SD, standard deviation; ER, emergency room. 
Table 4 AEs ( $\geq 1 \%$ in either treatment group), SAEs and discontinuations due to AEs and SAEs, $n$ (\%)

\begin{tabular}{|c|c|c|}
\hline Preferred term & $\begin{array}{l}\text { Glycopyrronium } \\
(n=305)\end{array}$ & $\begin{array}{l}\text { Placebo } \\
(n=154)\end{array}$ \\
\hline Patients with any AEs & $133(43.6)$ & $73(47.4)$ \\
\hline SAEs & $17(5.6)$ & $14(9.1)$ \\
\hline Death & $4(1.3)$ & I $(0.6)^{*}$ \\
\hline Discontinuation due to $\mathrm{AE}(\mathrm{s})$ & $8(2.6)$ & $3(1.9)$ \\
\hline Discontinuation due to $\mathrm{SAE}(\mathrm{s})$ & $5(1.6)$ & $3(1.9)$ \\
\hline Discontinuation due to non-SAE(s) & $4(1.3)$ & 0 \\
\hline \multicolumn{3}{|l|}{ Most common AEs } \\
\hline $\begin{array}{l}\text { Chronic obstructive pulmonary } \\
\text { disease }\end{array}$ & $58(19.0)$ & $39(25.3)$ \\
\hline Nasopharyngitis & $37(12.1)$ & $15(9.7)$ \\
\hline Upper respiratory tract infection & $18(5.9)$ & $12(7.8)$ \\
\hline Cough & $5(1.6)$ & $3(1.9)$ \\
\hline Hypertension & $5(1.6)$ & $3(1.9)$ \\
\hline $\begin{array}{l}\text { Upper respiratory tract infection } \\
\text { bacterial }\end{array}$ & $5(1.6)$ & $4(2.6)$ \\
\hline Benign prostatic hyperplasia & $4(1.3)$ & $\mathrm{I}(0.6)$ \\
\hline $\begin{array}{l}\text { Viral upper respiratory tract } \\
\text { infection }\end{array}$ & $4(1.3)$ & $\mathrm{I}(0.6)$ \\
\hline Pneumonia & $3(1.0)$ & $4(2.6)$ \\
\hline Dry mouth & $2(0.7)$ & $2(1.3)$ \\
\hline Abdominal distension & $\mathrm{I}(0.3)$ & $3(1.9)$ \\
\hline Dysuria & $\mathrm{I}(0.3)$ & $2(1.3)$ \\
\hline Hyperglycemia & 0 & $2(1.3)$ \\
\hline
\end{tabular}

Note: *The patient in the placebo group died in the follow-up period after the last dose of study drug.

Abbreviations: $\mathrm{AE}$, adverse event; $\mathrm{SAE}$, serious adverse event.

to evaluate the efficacy and safety of glycopyrronium in predominantly Chinese patients with moderate-to-severe COPD. The results of this study demonstrated that od glycopyrronium is efficacious in terms of improvement in lung function, dyspnea, health status, and reduction in symptom score and exacerbations compared with placebo over 26 weeks. The trough $\mathrm{FEV}_{1}$ with glycopyrronium was significantly improved versus placebo at Day 1, Weeks 12 and 26. Glycopyrronium also improved SGRQ total score and TDI focal score at Weeks 12 and 26. Risk of exacerbations, rescue medication use, and symptom score was reduced during the 26 week treatment period. The safety profile of glycopyrronium was found to be comparable to placebo.

The results of this study are consistent with earlier reported clinical trials of glycopyrronium, conducted predominantly in Caucasian populations. ${ }^{4,6,8}$ This result is supported by the pharmacokinetics of glycopyrronium where no clinically relevant differences have been found between Chinese and non-Chinese populations in its systemic exposure (Novartis data on file, 2012).

The management of COPD has developed significantly in the last decade with the availability of long-acting $\beta_{2}$-agonists, LAMAs and their combinations, which lead to substantial improvements in the outcome of patients in terms of lung function, exacerbations, and quality of life. Treatment with long-acting bronchodilators improved patients' functional status and quality of life by maintaining optimal lung function, improving symptoms, and preventing the recurrence of exacerbations. ${ }^{12}$ Glycopyrronium showed a rapid and sustained bronchodilation throughout the 26 week study period. In addition, a significant improvement in $\mathrm{FEV}_{1}$ at 5 minutes post-dose on Day 1 suggests that glycopyrronium could be beneficial for patients struggling with morning symptoms of COPD. ${ }^{13}$

Rapid and sustained bronchodilation in patients with moderate-to-severe COPD with glycopyrronium was associated with a significant improvement in dyspnea and health status versus placebo. ${ }^{6}$ In this study, improvement in lung function was accompanied by significant improvements in patient-reported outcomes (SGRQ and TDI). A systematic review of randomized clinical studies with inhaled longacting bronchodilators showed proportional improvement in health status with trough $\mathrm{FEV}_{1}$, but association between change in $\mathrm{FEV}_{1}$ and other patient-reported outcomes was generally weak. ${ }^{14}$ SGRQ represents a key patient-reported outcome that evaluates the overall health status of patients, whereas dyspnea is a common and most troublesome symptom of COPD. Improvement in health status and relief from dyspnea are important goals of the management of COPD.

Exacerbations are generally associated with a rapid decline in lung function and worse health outcomes in patients with COPD and may require emergency room visits or hospitalization with significant associated costs..$^{15}$ Reduction in exacerbations is one of the major components of management of COPD. In this study, glycopyrronium showed a trend towards reduction in the risk of exacerbation both in terms of rate and time to first moderate and severe COPD exacerbations, although this finding did not reach statistical significance. These outcomes are consistent with other LAMAs like tiotropium and aclidinium. In patients with moderate-to-severe COPD, tiotropium numerically reduced the risk of exacerbations during 26 week treatment period versus placebo. ${ }^{16}$ Aclidinium, a twice-daily LAMA also showed a numerical reduction in risk of exacerbation compared with placebo in the ACCLAIM/COPD I clinical study. ${ }^{17}$ The result of nonsignificant improvement in this study is not surprising, as the study was not powered for exacerbations and the overall rate of exacerbations in the study was comparatively low (annual exacerbation rate of 0.59 in the placebo arm of this study, compared with 2.20 reported elsewhere). ${ }^{18}$

Further to the above results, reduction in rescue medication use and symptom scores with glycopyrronium also 
supported the improvement in dyspnea and overall health status. Superior efficacy of glycopyrronium over placebo also resulted in less resource utilization during the study.

The incidence of AEs was generally low and comparable between the study groups, and most AEs were either mild or moderate in severity. A lower proportion of patients experienced severe AEs with glycopyrronium (4.3\%) compared with placebo $(8.4 \%)$. Worsening of COPD was the most frequent $\mathrm{AE}$ which occurred less frequently in patients with glycopyrronium compared with placebo. The proportion of patients with SAEs was also lower with glycopyrronium (5.6\%) compared with placebo $(9.1 \%)$. These data provide further support for the favorable safety profile of glycopyrronium, which is consistent with reported studies where glycopyrronium had a comparable safety profile with placebo or active comparators. ${ }^{4,6,8}$ Furthermore, no clinically relevant changes in QTc, changes in pulse rate, urinalysis, routine hematology, biochemistry, or blood pressure were observed with glycopyrronium during the study. This fact is supported by the previous findings where glycopyrronium, at supratherapeutic doses, did not show any clinically relevant effect on QT interval. ${ }^{19}$ In this study, CCV events were similar between the treatment groups. The reason for the numerical imbalance in deaths was not entirely clear, as baseline risk factors were generally well balanced between the treatment groups. However, percentage of patients with severe COPD and ICS use at baseline was slightly higher in the glycopyrronium group compared to placebo. But, the observed differences do not preclude the possibility that this numerical imbalance in death occurred by chance. Overall, the small imbalance of the death cases was not considered clinically meaningful and none of the deaths were related to the treatments.

Overall, the results from the GLOW7 study demonstrated the efficacy of glycopyrronium over 26 weeks in patients with moderate-to-severe COPD. Glycopyrronium showed a rapid onset of action and sustained bronchodilation compared with placebo. This study in predominantly Chinese patients with moderate-to-severe COPD supports the use of the approved therapeutic dose of od glycopyrronium $50 \mu \mathrm{g}$ as an effective and well-tolerated treatment option in the management of stable COPD.

\section{Acknowledgments}

The authors thank the patients who participated and the staff at the participating clinical centers. The study was funded by Novartis Pharma AG, Basel, Switzerland. The authors were assisted in the preparation of the manuscript by Santanu Sannigrahi of Novartis Healthcare Pvt Ltd, Hyderabad, India.

\section{Disclosure}

This study was sponsored by Novartis Pharma AG. Prof Chen Wang, ProfTieying Sun and ProfYijiang Huang do not have any conflicts of interest. Michael Humphries, Lingyan Bai, Lilly Li, Qian Wang, Pearl Kho, Roz Firth and Peter D'Andrea are employees of the study sponsor, Novartis and do not have any other conflicts of interest. This study was published as an abstract and presented at the American Thoracic Society International Conference 2014.

\section{References}

1. Soriano JB, Lamprecht B. Chronic obstructive pulmonary disease: a worldwide problem. Med Clin North Am. 2012;96(4):671-680.

2. Fang X, Wang X, Bai C. COPD in China: The burden and importance of proper management. Chest. 2011;139(4):920-929.

3. Global Initiative for Chronic Obstructive Lung Disease [homepage on the Internet]. Global Strategy for the Diagnosis, Management and Prevention of COPD; 2014. Available from: http://www.goldcopd.org/. Accessed April 8, 2014.

4. D'Urzo A, Ferguson GT, van Noord JA, et al. Efficacy and safety of once-daily NVA237 in patients with moderate-to-severe COPD: the GLOW1 trial. Respir Res. 2011;12:156.

5. Kerwin E, Hebert J, Gallagher N, et al. Efficacy and safety of NVA237 versus placebo and tiotropium in patients with COPD: the GLOW2 study. Eur Respir J. 2012;40(5):1106-1114.

6. D'Urzo A, Kerwin E, Overend T, D'Andrea P, Chen H, Goyal P. Once daily glycopyrronium for the treatment of COPD: pooled analysis of the GLOW1 and GLOW2 studies. Cur Med Res Opin. 2014;30(3): 493-508.

7. Chapman KR, Beeh KM, Beier J, et al. A blinded evaluation of the efficacy and safety of glycopyrronium, a once-daily long-acting muscarinic antagonist, versus tiotropium, in patients with COPD: the GLOW5 study. BMC Pulmon Med. 2014;14:4.

8. Beeh KM, Singh D, Di Scala L, Drollmann A. Once-daily NVA237 improves exercise tolerance from the first dose in patients with COPD: the GLOW3 trial. Int J COPD. 2012;7:503-513.

9. Kirkpatrick dP, Dransfield MT. Racial and sex differences in chronic obstructive pulmonary disease susceptibility, diagnosis, and treatment. Curr Opin Pulmon Med. 2009;15(2):100-104.

10. Martin A, Badrick E, Mathur R, Hull S. Effect of ethnicity on the prevalence, severity, and management of COPD in general practice. Brit J Gen Pract. 2012;62(595):e76-e81.

11. Yasuda SU, Zhang L, Huang SM. The role of ethnicity in variability in response to drugs: focus on clinical pharmacology studies. Clin Pharmacol Ther. 2008;84(3):417-423.

12. Jones R, Ostrem A. Optimising pharmacological maintenance treatment for COPD in primary care. Prim Care Respir J. 2011;20(1):33-45.

13. Roche N, Small M, Broomfield S, Higgins V, Pollard R. Real World COPD: Association of Morning Symptoms with Clinical and Patient Reported Outcomes. COPD. 2013;10(6):679-686.

14. Westwood M, Bourbeau J, Jones PW, Cerulli A, Capkun-Niggli G, Worthy G. Relationship between FEV1 change and patient-reported outcomes in randomised trials of inhaled bronchodilators for stable COPD: a systematic review. Respir Res. 2011;12:40.

15. Anzueto A. Impact of exacerbations on COPD. Eur Respir Rev. 2010;19(116):113-118.

16. Donohue JF, Fogarty C, Lotvall J, et al. Once-daily bronchodilators for chronic obstructive pulmonary disease: indacaterol versus tiotropium. Am J Respir Crit Care Med. 2010;182(2):155-162.

17. Jones PW, Rennard SI, Agusti A, et al. Efficacy and safety of oncedaily aclidinium in chronic obstructive pulmonary disease. Respir Res. 2011;12:55 
18. Matthys H, Pliskevich DA, Bondarchuk OM, Malek FA, Tribanek M, Kieser M. Randomised, double-blind, placebo-controlled trial of EPs 7630 in adults with COPD. Respir Med. 2013;107(5): 691-701.
19. Drollman A, Sechaud R, Pal P, Hara H, Uziel-Fusi S, Winkle P. Glycopyrronium does not affect QT interval in healthy subjects: a randomized, three-period, cross-over, placebo- and positive-controlled study. Int J Clin Pharmacol Ther. 2014;52(9):739-745. 


\section{Supplementary material \\ Inclusion and exclusion criteria \\ Inclusion criteria}

- Male or female patients aged $\geq 40$ years, who had signed an informed consent form prior to initiation of any studyrelated procedure.

- Patients with moderate-to-severe stable chronic obstructive pulmonary disease (COPD; stage II or stage III) according to the Global Initiative for Chronic Obstructive Lung Disease (GOLD 2010) guidelines.

- Current or ex-smokers who had a smoking history of at least 10 pack-years (10 pack-years was defined as 20 cigarettes a day for 10 years, or ten cigarettes a day for 20 years, etc).

- Patients with a post-bronchodilator forced expiratory volume in 1 second $\left(\mathrm{FEV}_{1}\right) \geq 30 \%$ and $<80 \%$ of the predicted normal and post-bronchodilator $\mathrm{FEV}_{1} /$ forced vital capacity $<0.7$ at visit two (day -14 ; post refers $\mathrm{FEV}_{1}$ and forced vital capacity after 45 minutes of administering ipratropium).

- Symptomatic patients, according to daily electronic diary data between visit two (day -14) and visit three (Day 1), with a total score of 1 or more on at least 4 of the last 7 days prior to visit three.

\section{Exclusion criteria}

- Pregnant women or nursing mothers (pregnancy confirmed by human chorionic gonadotropin laboratory test).

- Women of child-bearing potential.

- Patients with a history of long QT interval syndrome or whose corrected QTc measured at visit one (Fridericia method) was prolonged ( $>450 \mathrm{~ms}$ for males and females), as confirmed by the central electrocardiogram (ECG) interpretation.

- Patients who had a clinically significant abnormality on the ECG at visit one, who in the judgment of the investigator, would be at potential risk if enrolled into the study.

- Patients who, in the judgment of the investigator, had a clinically relevant laboratory abnormality or a clinically significant condition before visit three, such as (but not limited to):

o unstable ischemic heart disease, left ventricular failure (New York Heart Association class III or IV), history of myocardial infarction, arrhythmia;

o paroxysmal (eg, intermittent) atrial fibrillation and with persistent atrial fibrillation as defined by continuous atrial fibrillation for at least 6 months and controlled with a rate control strategy (ie, beta blocker, calcium channel blocker, pacemaker placement, digoxin or ablation therapy) for at least 6 months could be considered for inclusion;

o narrow-angle glaucoma;

o severe renal impairment;

o uncontrolled diabetes.

- Patients contraindicated for treatment with, or having a history of reactions/hypersensitivity to any of the following inhaled drugs, drugs of a similar class or any component thereof: anticholinergic agents, short-acting $\beta_{2}$-agonists, sympathomimetic amines, lactose, or any of the other excipients.

- Patients with a history of malignancy of any organ system (including lung cancer), treated or untreated, within the past 5 years whether or not there was evidence of local recurrence or metastases, with the exception of localized basal cell carcinoma of the skin.

- Patients with symptomatic prostatic hyperplasia, bladderneck obstruction or urinary retention were excluded from the study. Patients who had undergone full re-section of the prostate were considered for the study, as well as patients who were asymptomatic and stable on pharmacological treatment for the condition).

- Patients who had not achieved an acceptable spirometry result at visit two.

\section{COPD-specific exclusion criteria}

- Patients with any history of asthma indicated by (but not limited to) a blood eosinophil count $>600 / \mathrm{mm}^{3}$ (at visit two) or onset of symptoms prior to age 40 years and patients without asthma but who had a blood eosinophil count $>600 / \mathrm{mm}^{3}$ at visit two were excluded.

- Patients with concomitant pulmonary disease, eg, pulmonary tuberculosis (unless confirmed by imaging to be no longer active) or clinically significant bronchiectasis, sarcoidosis and interstitial lung disorder.

- Patients with lung lobectomy or lung volume reduction or lung transplantation.

- Patients with known history and diagnosis of $\alpha-1$ antitrypsin deficiency.

- Patients with allergic rhinitis who used an $\mathrm{H}_{1}$ antagonist or intra-nasal corticosteroids intermittently (treatment with a stable dose is permitted).

- Patients requiring long-term oxygen therapy $(>15$ hours a day) on a daily basis for chronic hypoxemia.

- Patients who were participating in the active phase of a supervised pulmonary rehabilitation program. 
- Patients who had a COPD exacerbation that required treatment with antibiotics, systemic steroids (oral or intravenous) or hospitalization in the last year up to and including visit three or in the 6 weeks prior to visit one or between visit one and visit three.

o Patients who developed a COPD exacerbation between screening (visit one) and randomization (visit three) were not eligible but were permitted to be re-screened after a minimum of 6 weeks after the resolution of the COPD exacerbation.

- Patients who had had a respiratory tract infection within 4 weeks prior to visit one.

o Patients who developed a respiratory tract infection during the screening period (up to visit three) were not eligible, but were permitted to be re-screened 6 weeks after the resolution of the respiratory tract infection.

\section{Sample size calculation}

The superiority of glycopyrronium $50 \mu \mathrm{g}$ once daily over placebo was evaluated by testing the following null hypothesis (H0) versus the alternative hypothesis (Ha):

- H0: there was no difference in the trough in $\mathrm{FEV}_{1}$ for patients with COPD treated with glycopyrronium $50 \mu \mathrm{g}$ versus placebo.

- Ha: there was a difference in the trough in $\mathrm{FEV}_{1}$ for patients with COPD treated with glycopyrronium $50 \mu \mathrm{g}$ versus placebo.

A proposed sample size of 450 patients (300 patients for glycopyrronium $50 \mu \mathrm{g}$ and 150 patients for placebo) was adjusted with $20 \%$ dropout at 26 weeks ( 360 patients estimated to complete the study). This total sample size has $95 \%$ power to detect a difference of $100 \mathrm{~mL}$ trough $\mathrm{FEV}_{1}$ between glycopyrronium and placebo assuming standard deviation of $245 \mathrm{~mL}$. Assumptions were based on historical data.

\section{Publish your work in this journal}

The International Journal of COPD is an international, peer-reviewed journal of therapeutics and pharmacology focusing on concise rapid reporting of clinical studies and reviews in COPD. Special focus is given to the pathophysiological processes underlying the disease, intervention programs, patient focused education, and self management protocols.
This journal is indexed on PubMed Central, MedLine and CAS. The manuscript management system is completely online and includes a very quick and fair peer-review system, which is all easy to use. Visit http://www.dovepress.com/testimonials.php to read real quotes from published authors. 